\title{
HER2 Type Male Breast Cancer Successfully Treated with Pertuzumab, Trastuzumab, and Eribulin Therapy: A Case Report
}

\author{
Masahiro Kitada*, Shunsuke Yasuda, Masahiro Abe, Nana Yoshida, Satoshi Okazaki, \\ Kei Ishibashi \\ Department of Breast Disease Center, Asahikawa Medical University, Asahikawa, Japan \\ Email: ^k1111@asahikawa-med.ac.jp, s-yasuda@asahikawa-med.ac.jp, abem@asahikawa-med.ac.jp, kyokui080026@gmail.com, \\ syugoshin.19851221@gmail.com, kei_dod@hotmail.com
}

How to cite this paper: Kitada, M., Yasuda, S., Abe, M., Yoshida, N., Okazaki, S. and Ishibashi, K. (2020) HER2 Type Male Breast Cancer Successfully Treated with Pertuzumab, Trastuzumab, and Eribulin Therapy: A Case Report. Journal of Cancer Therapy, 11, 154-159.

https://doi.org/10.4236/jct.2020.113013

Received:February 23, 2020

Accepted: March 22, 2020

Published: March 25, 2020

Copyright $\odot 2020$ by author(s) and Scientific Research Publishing Inc. This work is licensed under the Creative Commons Attribution International License (CC BY 4.0).

http://creativecommons.org/licenses/by/4.0/ (c) (i) Open Access

\begin{abstract}
Background: Male breast cancer is rare, accounting for approximately $0.5 \%$ $1.0 \%$ of all breast cancer cases; hormone-dependent luminal type male breast cancer is the most common. The proportion of hormone receptor-negative and human epithelial growth factor Receptor type 2-positive breast cancer is extremely low among male breast cancer. A patient with advanced HER2 type breast cancer, a rare male breast cancer, was successfully treated with pertuzumab, trastuzumab, and eribulin therapy. Case Presentation: A 75year-old man presented to our hospital with induration of the right anterior chest and lymphoedema of the right upper limb. Based on the results of core needle biopsy, he was diagnosed with HER2 type invasive ductal carcinoma associated with bone metastasis (stage IV). Chemotherapy with pertuzumab, trastuzumab, and eribulin was started. The drugs were remarkably effective, and his lymphoedema tended to improve. Conclusion: We reported a successful case of chemotherapy and targeted therapy for a rare male breast cancer of HER2 positive and hormone negative type.
\end{abstract}

\section{Keywords}

Male Breast Cancer, HER2 Type

\section{Background}

Male breast cancer (MBC) is rare, accounting for approximately $0.5 \%-1.0 \%$ of all breast cancer cases; hormone-dependent luminal type $\mathrm{MBC}$ is the most common. 
The proportion of hormone receptor-negative and Human Epithelial growth factor Receptor type 2 (HER2)-positive breast cancer is extremely low among MBCs and accounts for $0.6 \%-1.2 \%$ of MBCs; in such cases, the prognosis is often poor [1] [2] [3] [4]. Herein, we report our experience with advanced hormone receptor-negative and HER2-positive breast cancer.

\section{Case}

The patient visited our department with a 3-month history of induration of the right anterior chest, right upper limb edema, numbness, and pain. His height was $158 \mathrm{~cm}$ and weight was $59 \mathrm{~kg}$. Induration with redness and nodules was observed on the entire right anterior chest; we also observed edema from the right neck to upper limb and enlarged axillary lymph nodes. Blood test showed no abnormal findings except for increased tumor marker levels (carcinoembryonic antigen (CEA), $50.7 \mathrm{ng} / \mathrm{mL}$ and cancer antigen 15-3 (CA15-3), $295 \mathrm{U} / \mathrm{mL}$ ). Computer tomography (CT) revealed nodules right under the papilla and surrounding edema, a number of enlarged lymph nodes from the axilla to the right neck, lymphedema in the upper limb, and pleural effusion in the right lung (Figure 1). Positron emission tomography (FDG-PET) revealed multiple accumulations in the entire right mammary gland (maximum standardized uptake value, 6.8), enlarged lymph nodes from the right cervical to axillary regions and in the left axillary regions, and multiple accumulations in the ribs and spine (Figure 2). Core needle biopsy revealed invasive ductal carcinoma: histological grade II; Ki-67 index, 50\%; estrogen receptor (ER) (-); progesterone receptor (PgR) (-); HER2 (3+); intrinsic subtype, HER2 type; and T4N3M1 Stage IV. We considered administration of pertuzumab, trastuzumab, and docetaxel; however, considering pleural effusion and edema from the right anterior chest to the upper limb, we initiated combination therapy with pertuzumab, trastuzumab, and eribulin. After completing 1 cycle, his edema and upper limb pain decreased markedly. After completing 3 cycles, CT showed reduction in lymph node swelling; moreover, a marked decrease was observed in tumor marker levels (CEA, $5.8 \mathrm{ng} / \mathrm{mL}$ and CA15-3, 57.5 U/mL) (Figure 3). He maintained partial response with chemotherapy, and no adverse reactions were observed. The treatment is still ongoing.
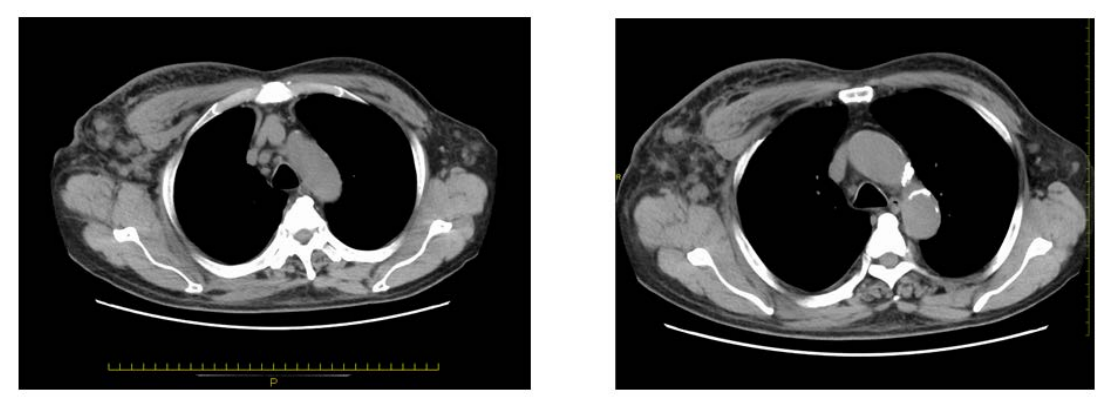

Figure 1. CT image at first visit: right axilla, cervical lymphadenopathy, mediastinal lymphadenopathy, right upper limb edema. 

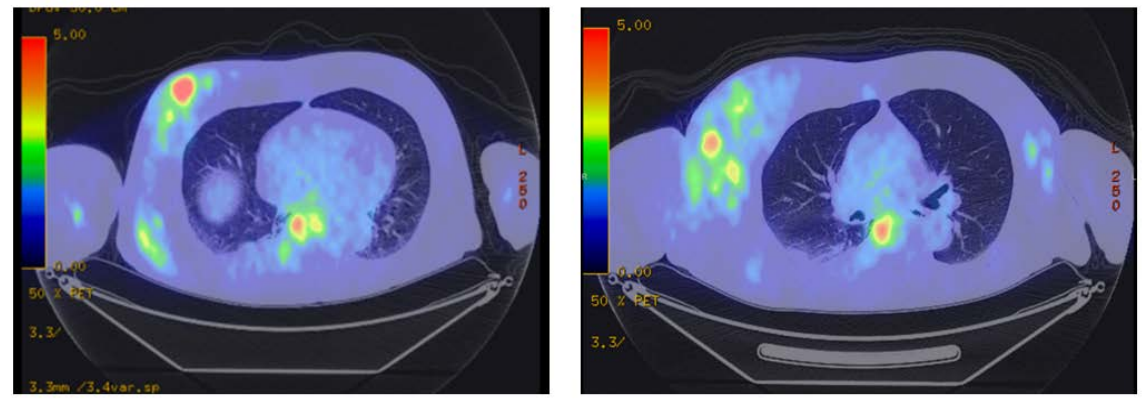

Figure 2. Positron emission tomography (FDG-PET) revealed multiple accumulations in the entire right mammary gland (maximum standardized uptake value, 6.8), enlarged lymph nodes from the right cervical to axillary regions and in the left axillary regions, and multiple accumulations in the ribs and spine.
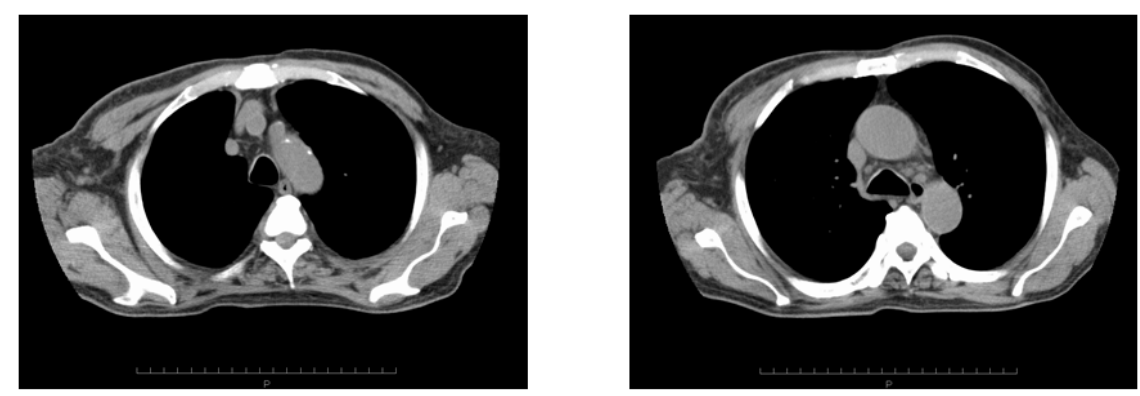

Figure 3. CT image after completing 3 cycles chemotherapy, CT showed reduction in lymph node swelling.

\section{Discussion}

$\mathrm{MBC}$ is rare, accounting for $0.5 \%-1.0 \%$ of all breast cancer cases; hormonedependent luminal type $\mathrm{MBC}$ is the most common. The proportion of intrinsic HER2 subtype (hormone receptor-negative and HER2-positive) cancers among MBCs is as low as $0.6 \%-1.2 \%$. Patients with advanced recurrent breast cancer often have a poor prognosis [1] [2] [3] [4]. Of the 3194 breast cancer patients at our hospital between 2000 and 2018, 14 (0.44\%) had MBC. Twelve patients had hormone-dependent (ER- and/or PgR-positive) and HER2-negative cancers. Of these, 10 patients are still alive without recurrence after oral administration of tamoxifen for 5 years; 2 patients with stage IIIb and stage IV disease at the initial visit died after 1 year and 8 months and 5 years and 8 months, respectively. One patient with hormone receptor-negative and HER2-positive breast cancer died early from multiple lymph nodes and lung metastases. Taken together, we believe that HER2 type MBCs are detected in the advanced stage.

In general, a combination of anticancer and anti-HER2 therapy is the standard treatment for HER2-positive advanced recurrent breast cancer. Recently, the usefulness of pertuzumab, trastuzumab, and docetaxel has also been reported [5]. However, docetaxel administration in patients with edema or pleural effusion requires careful attention, and its use is often difficult. In the 3rd ESOESMO International Consensus Guidelines for Advanced Breast Cancer (ABC 
3), pertuzumab and trastuzumab were suggested to be good (easy to use) anticancer drugs in response to the HER2 positive ABC-Unanswered Questions for HER2 positivity: "Are there better chemo partners with less toxicity for pertuzumab and trastuzumab first line?" [6]. A phase II clinical study on pertuzumab, trastuzumab, and eribulin therapy has also been conducted. Thus, we decided to use eribulin in the present patient [7]. A phase III study compared previous taxane/anthracycline therapy with eribulin-containing therapy (selected by attending physicians) in terms of survival benefit in patients with advanced recurrent breast cancer. Their results showed that response rate, progression-free survival, and median overall survival were significantly high whereas adverse reactions (such as peripheral neuropathy) were significantly low in the eribulin group. Furthermore, subgroup analysis showed favorable results in HER2-positive patients [8]. Considering the limited reports on HER2-positive MBC and lack of data supporting differences in treatment between men and women, we considered it appropriate to refer to such clinical studies for treatment in our present case.

Furthermore, genetic breast cancer accounts for 5\% - 10\% of breast cancer cases, and the proportion of breast cancer susceptibility gene (BRCA) mutation-positivity is reportedly higher in $\mathrm{MBC}$ than in female breast cancers [9] [10]. $B R C A$ mutation-positive patients generally show HER2 negativity. This is because both HER2 loci are located close to the $B R C A-1$ gene; furthermore, a report has suggested that $8 \%-10 \% B R C A$ mutation-positive patients are HER2positive [11]. Unlike anticancer drugs, poly ADP-ribose polymerase (PARP) inhibitors [12], which are currently available for patients with BRCA mutation-positive advanced cancers, are relatively easy to use even in poor general conditions. BRCA mutation testing may be an option, considering the use of PARP inhibitors, in patients who are not eligible for receiving many drug alternatives, as observed in this case.

\section{Conclusion}

We reported a successful case of chemotherapy and targeted therapy for a rare male breast cancer of HER2 positive and hormone negative type.

\section{Availability of Data and Materials}

All data generated or analyzed during this study are included in this published article.

\section{Ethics Approval and Consent to Participate}

All procedures used in this research were approved by the Ethics Committee of Asahikawa Medical University.

\section{Authors Contribution}

MK has operated this case and analyzed all data. SY, MA, NY, SO, KI did the as- 
sistant of chemotherapy. All authors read and approved the final manuscript.

\section{Consent for Publication}

Written informed consent was obtained from the patient for the publication of this case report and any accompanying images. A copy of the written consent form is available for review by the Editor-in-Chief of this journal.

\section{Conflicts of Interest}

The authors declare that they have no competing interests.

\section{References}

[1] Leone, J.P., Leone, J., Zwenger, A.O., Iturbe, J., Vallejo, C.T. and Leone, B.A. (2015) Prognostic significance of tumor subtypes in male breast cancer: a population-based study. Breast Cancer Research and Treatment, 152, 601-609. https://doi.org/10.1007/s10549-015-3488-y

[2] Masci, G., Caruso, M., Caruso, F., Salvini, P., Carnaghi, C., Giordano, L., Miserocchi, V., Losurdo, A., Zuradelli, M., Torrisi, R., Di Tommaso, L., Tinterri, C., Testori, A., Garcia-Etienne, C.A., Gatzemeier, W. and Santoro, A. (2015) Clinicopathological and Immunohistochemical Characteristics in Male Breast Cancer: A Retrospective Case Series. Oncologist, 20, 586-592.

https://doi.org/10.1634/theoncologist.2014-0243

[3] Chavez-Macgregor, M., Clarke, C.A., Lichtensztajn, D., Hortobagyi, G.N. and Giordano, S.H. (2013) Male Breast Cancer According to Tumor Subtype and Race: A Population-Based Study. Cancer, 119, 1611-1617. https://doi.org/10.1002/cncr.27905

[4] Abreu, M.H., Afonso, N., Abreu, P.H., Menezes, F., Lopes, P., Henrique, R., Pereira, D. and Lopes, C. (2016) Male Breast Cancer: Looking for Better Prognostic Subgroups. The Breast, 26, 18-24. https://doi.org/10.1016/j.breast.2015.12.001

[5] Baselga, J., Cortés, J., Kim, S.B., Im, S.A., Hegg, R., Im, Y.H., Roman, L., Pedrini, J.L., Pienkowski, T., Knott, A., Clark, E., Benyunes, M.C., Ross, G. and Swain, S.M. (2012) CLEOPATRA Study Group. Pertuzumab plus Trastuzumab plus Docetaxel for Metastatic Breast Cancer. The New England Journal of Medicine, 366, 109-111. https://doi.org/10.1056/NEaJMoa1113216

[6] Cardoso, F., Costa, A., Senkus, E., Aapro, M., André, F., Barrios, C.H., Bergh, J., Bhattacharyya, G., et al. (2017) 3rd ESO-ESMO International Consensus Guidelines for Advanced Breast Cancer (ABC 3). The Breast, 31, 244-259. https://doi.org/10.1016/j.breast.2017.01.001

[7] Narui, K., Yamashita, T., Kitada, M., Kawaguchi, H., Hattori, M., et al. (2017) Eribulin in Combination with Pertuzumab plus Trastuzumab for HER2-Positive Advanced or Recurrent Breast Cancer (JBCRG-M03). Journal of Clinical Oncology, 35, 1025-1025. https://doi.org/10.1200/JCO.2017.35.15_suppl.1025

[8] Cortes, J., O'Shaughnessy, J., Loesch, D., Blum, J.L., Vahdat, L.T., Petrakova, K., Chollet, P., Manikas, A., Diéras, V., Delozier, T., Vladimirov, V., Cardoso, F., Koh, H., Bougnoux, P., Dutcus, C.E., Seegobin, S., Mir, D., Meneses, N., Wanders, J. and Twelves, C. (2011) EMBRACE (Eisai Metastatic Breast Cancer Study Assessing Physician's Choice Versus E7389) Investigators. Eribulin Monotherapy versus Treatment of Physician's Choice in Patients with Metastatic Breast Cancer (EMBRACE): A Phase 3 Open-Label Randomised Study. Lancet, 377, 914-923. 
https://doi.org/10.1016/S0140-6736(11)60070-6

[9] Kwiatkowska, E., Teresiak, M., Filas, V., Karczewska, A., Breborowicz, D. and Mackiewicz, A. (2003) BRCA2 Mutations and Androgen Receptor Expression as Independent Predictors of Outcome of Male Breast Cancer Patients. Clinical Cancer Research, 9, 4452-4459.

[10] Hesse-Biber, S. and An, C. (2017) Within-Gender Differences in Medical Decision Making among Male Carriers of the BRCA Genetic Mutation for Hereditary Breast Cancer. American Journal of Men's Health, 11, 1444-1459. https://doi.org/10.1177/1557988315610806

[11] Vaziri, S.A., Krumroy, L.M., Elson, P., Budd, G.T., Darlington, G., Myles, J., Tubbs, R.R. and Casey, G. (2001) Breast Tumor Immunophenotype of BRCA1-Mutation Carriers Is Influenced by Age at Diagnosis. Clinical Cancer Research, 7, 1937-1945.

[12] Tutt, A., Robson, M., Garber, J.E., Domchek, S.M., Audeh, M.W., Weitzel, J.N., Friedlander, M., Arun, B., Loman, N., Schmutzler, R.K., Wardley, A., Mitchell, G., Earl, H., Wickens, M. and Carmichael, J. (2010) Oral Poly(ADP-ribose) Polymerase Inhibitor Olaparib in Patients with BRCA1 or BRCA2 Mutations and Advanced Breast Cancer: A Proof-Of-Concept Trial. Lancet, 376, 235-244. https://doi.org/10.1016/S0140-6736(10)60892-6

\section{Abbreviations}

HER2: Human Epithelial Growth factor Receptor type 2

MBC: Male Breast Cancer

CT: Computer Tomography

FDG-PET: Fluorodeoxyglucose-Positron Emission Tomography

CEA: Carcinoembryonic Antigen

CA15-3: Cancer Antigen 15-3

$B R C A$ : breast cancer susceptibility gene

PARP: Poly ADP-Ribose Polymerase 